\title{
Occipital Stimulation for Chronic Migraine: Patient Selection and Complications
}

\author{
Zelma H.T. Kiss, Werner J. Becker
}

\begin{abstract}
Background: Chronic migraine is a significant cause of disability world-wide and occipital region stimulation (OS) has been proposed to treat it. While participating in an industry-sponsored pilot trial of OS, we aimed to collect data regarding our surgical complications and long term usage of OS in our chronic migraine patients. Methods: Ten patients ( 8 female, median age 46.5 years) were enrolled based on criteria established by the sponsoring company, screened in the headache clinic, and followed for a median of 33 months. We did not access data collected by industry for this report and instead collected our own data prospectively, including predominant location of headache, location of paresthesia evoked by OS, and complications. Results: Adverse events included three possible early infections requiring antibiotics but not hardware removal, one late implantable pulse generator erosion requiring removal, one generator malfunction requiring revision, and loss of paresthetic coverage requiring four revisions in four patients. Two patients experienced new symptoms requiring psychiatric intervention. Five patients had no benefit and have been explanted. Of those who remain using their device, the proportion of their pre-operative pain located in the occipital region was $0.62 \pm 0.14$, whereas in those patients who have been explanted, the proportion was $0.31 \pm 0.18(\mathrm{t}=3.15, \mathrm{p}=0.01)$. Conclusions: Complication rates with OS are higher than those seen with other stimulation techniques, despite identical hardware and similar surgery. The location of migraine pain did predict outcome, and suggests that only those with primarily occipital region headache are candidates for this therapy.
\end{abstract}

RÉSUMÉ: Stimulation occipitale dans la migraine chronique : sélection des patients et complications. Contexte : La migraine chronique est une cause importante d'invalidité à l'échelle mondiale et la stimulation de la région occipitale (SO) a été proposée comme traitement de cette maladie. Lors de notre participation à un projet pilote sur la $\mathrm{SO}$, commandité par l'industrie, nous avons recueilli des données sur les complications chirurgicales que nous avons observées et sur l'utilisation à long terme de la $\mathrm{SO}$ chez nos patients atteints de migraine chronique. Méthode : Dix patients dépistés à notre clinique de la céphalée, qui satisfaisaient aux critères de sélection déterminés par le commanditaire, ont été inclus dans l'étude dont 8 femmes et dont l'âge moyen était de 46,5 ans. La durée médiane du suivi a été de 33 mois. Nous n'avons pas eu recours aux données recueillies par le commanditaire pour effectuer cette étude. Nous avons plutôt recueilli nos propres données de façon prospective, dont la région prédominante de la céphalée, l'endroit des paresthésies provoquées par la SO et les complications de l'intervention. Résultats : Parmi les incidents thérapeutiques, nous avons noté 3 infections précoces ayant nécessité l'administration d'antibiotiques sans retrait de l'appareillage, une érosion tardive du neurostimulateur implantable ayant nécessité son retrait, un dysfonctionnement du neurostimulateur ayant nécessité une révision et la perte de la couverture paresthésique ayant nécessité 4 révisions chez 4 patients. Deux patients ont présenté de nouveaux symptômes qui ont nécessité une intervention psychiatrique. Cinq patients n'ont pas éprouvé de bénéfice et leur dispositif a été retiré. Chez ceux dont le dispositif est encore en place, la proportion de la douleur préopératoire localisée à la région occipitale était de $0,62 \pm 0,14$, alors que chez les patients explantés, la proportion était de $0,31 \pm 0,18(\mathrm{t}=3,15 ; \mathrm{p}=0,01)$. Conclusions : Les taux de complications de la SO sont plus élevés que ceux observés avec d'autres techniques de stimulation, malgré un appareillage et une chirurgie similaires. La localisation de la douleur migraineuse prédisait le résultat thérapeutique, ce qui suggère que seulement ceux qui ont une céphalée principalement occipitale sont des candidats à ce traitement.

Can J Neurol Sci. 2012; 39: 807-812

Headache, and specifically migraine, is one of the biggest causes of lost productivity in developed countries ${ }^{1,2}$. While there are numerous medical options to treat migraine, some patients progress to a chronic daily headache syndrome, chronic migraine. Diagnostic criteria for chronic migraine include headache on 15 days or more per month, with at least eight of these days continuing to meet migraine diagnostic criteria, or be successfully treated with migraine-specific drugs ${ }^{3}$. The development of chronic migraine is now considered one of the complications of migraine ${ }^{4}$. A recent management approach is occipital nerve stimulation, although more precisely should be called occipital region stimulation (OS) because the electrodes are placed in the subcutaneous tissue near the nerve, not on the nerve itself ${ }^{5}$. Success rates ranging from $50-90 \%{ }^{6-8}$ have been reported in open label single centre studies, including reduced headache days, severity of pain, disability, depression and pain impact scores 9 .

Three recent industry sponsored clinical trials reported different results at three month follow-up. The ONSTIM study ${ }^{10}$ reported a $39 \%$ responder rate, defined as a $50 \%$ reduction from

From the Division of Neurosurgery (ZHTK), Neurology (WJB), Department of Clinical Neurosciences, University of Calgary, Calgary, Alberta, Canada. Received February 6, 2012. Final Revisions Submitted May 9, 2012. Correspondence to: Zelma HT Kiss, Room 1AC58, HRIC, 3280 Hospital Drive NW, Calgary, Alberta, T2N 4N1, Canada. Email: zkiss@ucalgary.ca. 
baseline in headache days per month or a 3-point drop in severity of pain on a 10 point visual analog scale, in chronic migraine patients treated with OS in comparison to $6 \%$ in the sham OS and $0 \%$ in the medically managed groups. The PRISM trial was larger, was published only in abstract form, but failed to identify a difference in number of headache days in migraine sufferers with sham vs. active stimulation ${ }^{11}$. Interestingly the complications seen in these two trials were also different. The third large trial funded by yet another industry competitor, has also only been reported in abstract form ${ }^{12}$, finding a very low complication rate of $1 \%$ and significant improvements in number of headache days, pain/distress scales and quality of life in those receiving active stimulation. In the ONSTIM study, $24 \%$ of subjects experienced lead migration at the three month time point. The PRISM group ${ }^{11}$ reported infection (15.1\%), non-target area sensory symptoms (18.0\%), implant site pain (17.3\%) and $6.8 \%$ lead migration over two years of follow-up. Both trials suggested that specific subgroups may have better response to therapy than others, although only in the PRISM trial did a specific subgroup undergo separate analysis ${ }^{11}$. Similarly a recent retrospective study identified the types of headache classes more likely to respond to this therapy?

There are several questions about OS for migraine that remain to be resolved. These include (i) who are the migraineurs most likely to respond to this surgery, and (ii) what are the complications of this procedure. We participated in the industry sponsored trial reported by Saper et $\mathrm{al}^{10}$ and collected data in our patients in a prospective manner as part of routine medical care to address these two questions.

\section{METHODS}

The patient sample reported here is from the multicentre study $^{10}$ registered with National Institutes of Health (NIH)
ClinicalTrials.gov (NCT00200109). We obtained institutional ethics approval for this trial.

Details of the study protocol, inclusion and exclusion criteria, outcome measures are reported in the multicentre trial ${ }^{10}$. Briefly all patients were screened in the headache clinic, deemed to be refractory to medical management (more than 15 headache days per month over three months) and had pain located in the occipital or suboccipital regions. However the amount of pain located in this region was not specified. The protocol did not require psychological screening, but did require the absence of medication overuse. Patients and evaluating clinicians were blinded for the first three months and the two groups consisted of patients who were allowed to control their own OS with their patient programmer and patients that was set to sham stimulation (1 minute of stimulation every 24 hours.

The surgical technique was dictated by the multicentre protocol. Briefly, patients were positioned awake in the lateral decubitus position and fluoroscopy in the AP plane utilized to pass spinal cord stimulation electrodes (PISCES QUAD 3487A, Medtronic, Minneapolis, MN) bilaterally from a midline incision at C2. Local anaesthesia and intravenous sedation allowed intraoperative testing to confirm adequate paresthetic coverage of the greater and lesser occipital nerve territories bilaterally. The Touhy needle provided in the kit was bent into a slight curve and passed from midline towards each mastoid process in the suprafascial plane. After confirming that the patient felt paresthesia in the greater and lesser occipital nerve territories, the lead was secured with a specially designed device (TITAN anchor, Medtronic Inc. Minneapolis, MN) to the fascia after leaving a loop of wire for strain relief in a subcutaneous pocket. The spinal cord leads were then tunnelled towards a scapular incision. Implantable pulse generators (IPG, Synergy 7427, Medtronic, Minneapolis, MN) were placed in the abdomen and

Table: Demographics and details of outcomes

\begin{tabular}{|c|c|c|c|c|c|c|c|c|}
\hline Subject & Sex & Age & $\begin{array}{l}\text { Other } \\
\text { conditions }\end{array}$ & $\begin{array}{l}\text { Location of } \\
\text { pain }\end{array}$ & $\begin{array}{l}\text { Trigger } \\
\text { points }\end{array}$ & Complications & Paresthesia & Outcome \\
\hline 1 & $\mathrm{~F}$ & 37 & & $\begin{array}{l}0.66 \text { occipital: } \\
0.33 \text { temporal }\end{array}$ & 5 & & $\begin{array}{l}\text { Almost full } \\
\text { coverage }\end{array}$ & Using at $36.1 \mathrm{~m}$ \\
\hline 2 & $\mathrm{~F}$ & 36 & & $\begin{array}{l}0.75 \text { occipital: } \\
0.25 \text { frontal }\end{array}$ & 3 & IPG failure, replaced & Full coverage & Using at $38.2 \mathrm{~m}$ \\
\hline 3 & $\mathrm{~F}$ & 55 & & $\begin{array}{l}0.6 \text { occipital: } \\
0.3 \text { temporal: } \\
0.1 \text { orbital }\end{array}$ & 4 & Revision of leads due to inadequate coverage & $\begin{array}{l}\text { Inadequate } \\
\text { coverage }\end{array}$ & Removed at $14.9 \mathrm{~m}$ \\
\hline $4 *$ & $\mathrm{~F}$ & 32 & & $\begin{array}{l}0.35 \text { occipital; } \\
0.65 \text { frontal }\end{array}$ & 1 & Psychiatric treatment & Full coverage & Removed at $7.2 \mathrm{~m}$ \\
\hline 5 & M & 49 & $\begin{array}{l}\text { Diabetes, } \\
\text { obesity }\end{array}$ & $\begin{array}{l}0.7 \text { occipital: } \\
0.1 \text { frontal: } \\
0.2 \text { temporal }\end{array}$ & 1 & $\begin{array}{l}\text { Incisional infection / inflammation, Revision } \\
\text { of L lead due to loss of coverage }\end{array}$ & $\begin{array}{l}\text { Almost full } \\
\text { coverage after } \\
\text { revision }\end{array}$ & Using at $35.9 \mathrm{~m}$ \\
\hline 6 & $\mathrm{~F}$ & 44 & $\begin{array}{l}\text { Bipolar } \\
\text { disorder }\end{array}$ & $\begin{array}{l}0.2 \text { occipital: } \\
0.4 \text { temporal: } \\
0.4 \text { orbital }\end{array}$ & 0 & $\begin{array}{l}\text { Incisional infection / inflammation } \\
\text { Narcotic addiction requiring psychiatric } \\
\text { admission }\end{array}$ & Full coverage & Removed at $33.9 \mathrm{~m}$ \\
\hline $7 *$ & $\mathrm{~F}$ & 58 & $\begin{array}{l}\text { Fibro- } \\
\text { myalgia }\end{array}$ & $\begin{array}{l}\text { Everywhere } \\
\text { (see Fig 3) }\end{array}$ & 10 & $\begin{array}{l}\text { Revision to regain coverage \& correct } \\
\text { extension tightening }\end{array}$ & $\begin{array}{l}\text { Local coverage } \\
\text { only }\end{array}$ & Removed at $27.0 \mathrm{~m}$ \\
\hline 8 & $\mathrm{M}$ & 54 & & $\begin{array}{l}0.6 \text { occipital: } \\
0.4 \text { frontal }\end{array}$ & 1 & & Partial coverage & Using at $33.2 \mathrm{~m}$ \\
\hline 9 & $\mathrm{~F}$ & 38 & $\begin{array}{l}\text { Morbid } \\
\text { obesity }\end{array}$ & $\begin{array}{l}0.4 \text { occipital: } \\
0.6 \text { frontal }\end{array}$ & 0 & $\begin{array}{l}\text { Incisional infection / inflammation, late } \\
\text { erosion requiring removal, } \\
\text { delayed re-implantation }\end{array}$ & Full coverage & $\begin{array}{l}\text { Using } 31.2 \mathrm{~m} \text { after first, } \\
6 \mathrm{~m} \text { since re-implant }\end{array}$ \\
\hline 10 & $\mathrm{~F}$ & 50 & & $\begin{array}{l}0.2 \text { occipital: } \\
0.8 \text { frontal }\end{array}$ & 6 & $\begin{array}{l}\text { Only R side implanted during first surgery, } \mathrm{L} \\
\text { side implanted } 4 \mathrm{~m} \text { later }\end{array}$ & Full coverage & Removed at $27.7 \mathrm{~m}$ \\
\hline
\end{tabular}

Subjects continuing to use their OS are shaded grey. Subjects in whom the IPG was placed in the buttock instead of abdomen are starred*. 

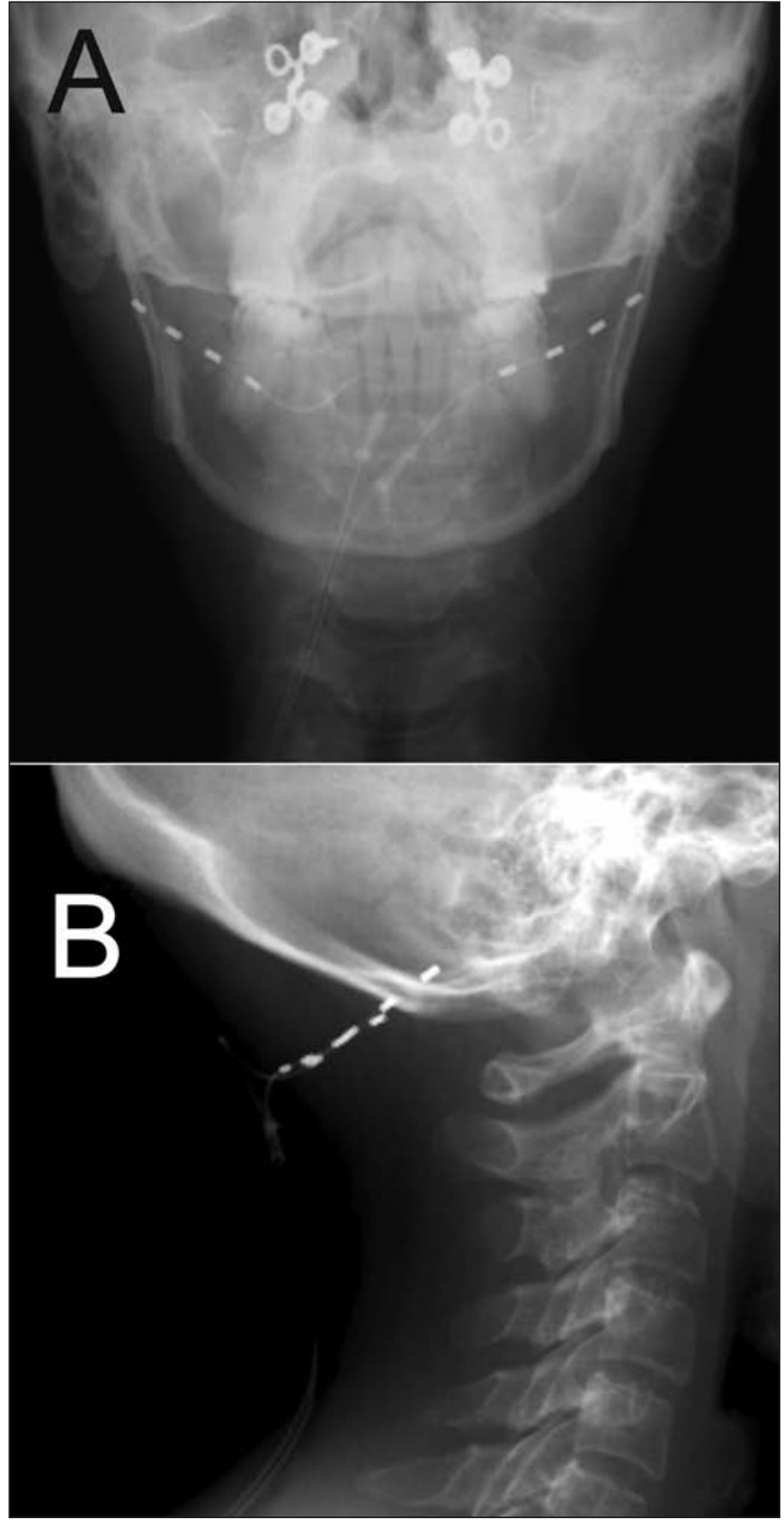

Figure 1: Skull and cervical spine radiographs showing example of ONS electrode location in $A P(A)$ and lateral $(B)$ views.

extensions were tunnelled from the scapular connector site to the IPG. Buttock placement of the IPG was allowed under exceptional circumstances and this was the case for two of our patients (Table). Three passes of the occipital electrode was allowed before a failure to achieve adequate paresthetic coverage ensued and the procedure aborted. Radiographs confirmed correct placement of the electrodes in the immediate postoperative period, at each follow-up, or if there was a change in paresthetic coverage (Figure 1).
Ten patients ( 8 female, median age 46.5 years) were enrolled and followed for a median of 33 months (range 7-38) (Table). We did not access the data collected through the multicentre trial for this report and instead collected our own data prospectively, as part of routine neurosurgical care. These data included predominant location of pain, location of paresthesia evoked by OS, surgical details, stimulation parameters utilized, and complications. Pre-operatively patients were questioned about the percent of their usual headache pain located in each part of the head or neck, and this was recorded on figurines (Figures 2, $3)$. Trigger points in the upper body and co-morbidities were recorded at baseline. Paresthesia induced by OS was noted on figurines at each follow-up appointment. The ONSTIM study protocol required three years of follow-up and we saw all patients yearly while they had an implanted system. Patients were not followed after device removal. For the purposes of this report, we defined responders as those patients who continue to use the ONS systems three years post-implant, and nonresponders as those who do not and/or have had their systems electively removed.

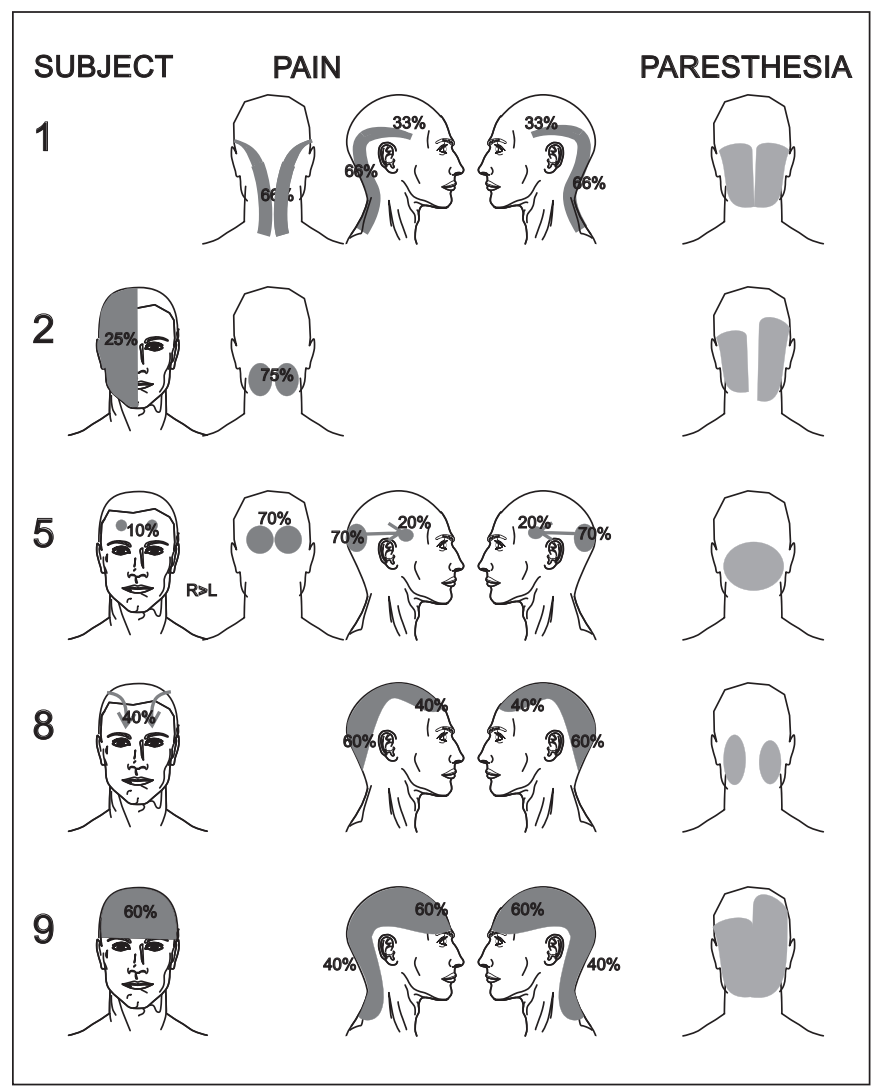

Figure 2: Examples of migraine headache pain locations (A) and paresthesia coverage $(B)$ in patients continuing to use OS. The arrows indicate that the pain travelled in the direction shown. For example, subject 8 described $60 \%$ of pain in the occipital region, but when headache became very severe occipitally, it travelled to the frontal region $40 \%$ of the time. 


\section{RESULTS}

The Table reports the demographic details and outcomes in our ten patients. Two patients had buttock placement of the IPG because of multiple abdominal procedures and hernias in one and plans for pregnancy in another. In one patient adequate paresthesia could not be obtained in the operating room during the initial procedure, therefore only one lead was implanted. The patient returned four months later for a delayed surgical placement on the other side.

\section{Surgical complications}

In the immediate post-operative period three patients experienced inflammation at surgical sites: two at the suboccipital and one at the abdominal incision. All three received intravenous followed by oral antibiotics although neither blood nor wound cultures identified bacterial growth and none required removal of hardware.

There was one delayed skin erosion in a morbidly obese patient, 21 months after initial implantation. This was the same patient who had an inflammation at the IPG site in the immediate post-operative period. The erosion likely occurred because the IPG rotated in the subcutaneous fat of her abdomen. The system was removed, and re-implanted 11 months later in the subclavicular region. In one patient, the IPG malfunctioned and was replaced 17 months post-operatively. This same patient complained about intermittent non-painful swelling at the IPG and occipital sites, however this was never witnessed by a health care professional.

\section{Other adverse events}

The most common adverse event was loss of paresthetic coverage requiring four revisions in four patients. These occurred at variable time points, from immediately to two years post-operatively. The most troubling adverse events involved psychiatric complications. One patient who had apparently stable bipolar disorder pre-operatively, required a three week hospital stay for narcotic addiction ten months post-implant. Another patient who had no prior psychiatric issues, experienced significant depression requiring in-patient management.

\section{Predictors of outcome}

Five patients experienced no benefit and their systems were explanted at 7.2-33.9 months. These five subjects were compared to the five who continue to use OS. Details of their outcomes are described in the multicentre study ${ }^{10}$ and are not the focus of this article. Instead we compared location of migraine pain on figurines, number of trigger points in the upper body, and co-morbidities at baseline in these two groups, as well as paresthesia coverage of the greater and lesser occipital nerve territories.

There was no significant difference in number of trigger points in the responders (as defined by continuing to use OS three years post-implant) in comparison to the non-responders (as defined by removed OS systems). However of the responders, the proportion of their pain located in the occipital region was $0.62 \pm 0.14$, whereas in the failures the proportion was $0.31 \pm 0.18(\mathrm{t}=3.15, \mathrm{p}=0.01)$. Of the five responding to OS, four had complete or almost complete paresthesia covering both

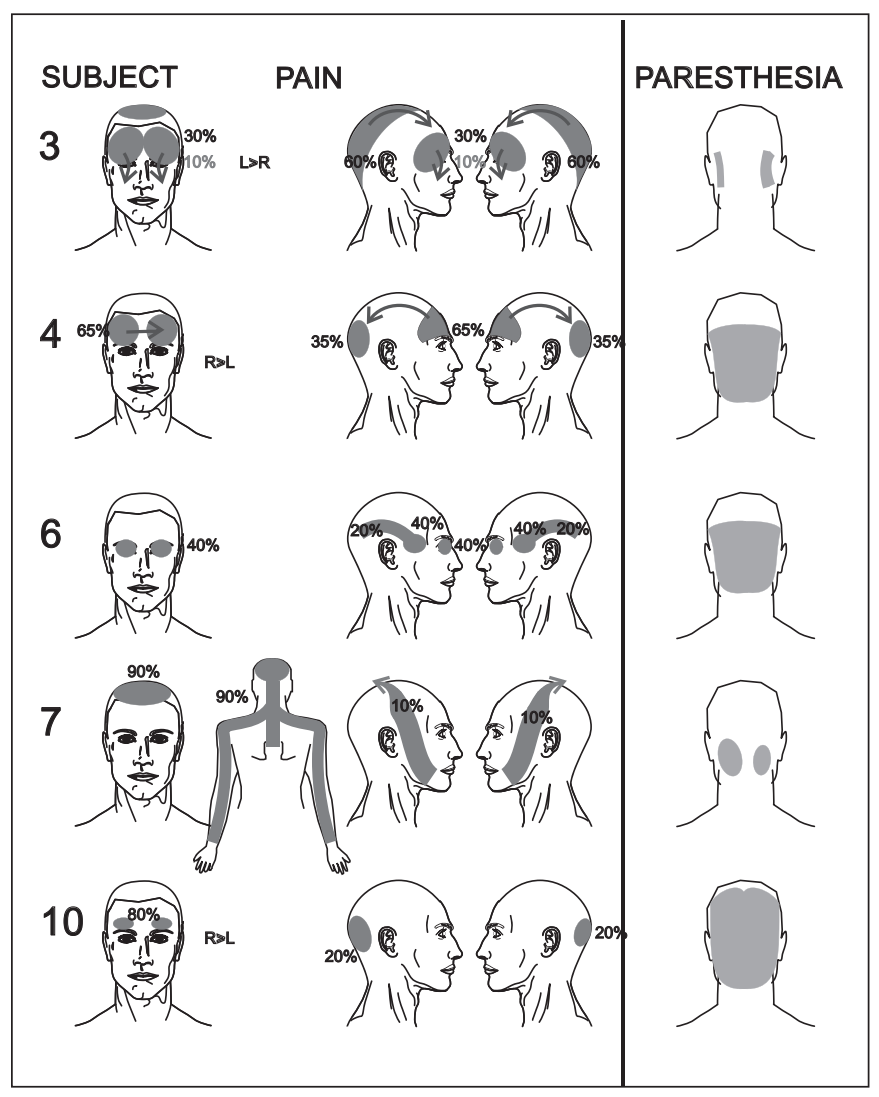

Figure 3: Examples of migraine headache pain locations (A) and paresthesia coverage $(B)$ in patients who failed to achieve benefit with OS.

greater and lesser occipital nerve territories, however in three of the five failures coverage was complete as well, but benefit was not realized. Pre-morbid medical issues, did not always predict outcome. For example, despite more complications in the two obese patients, they both continue to use OS. However, the one subject with a significant prior psychiatric history did not respond and had additional psychiatric issues arise.

\section{DisCuSSION}

In summary, based on our experience with ten patients, OS is more likely to provide benefit to migraineurs with predominantly occipital pain. Adverse events associated with OS for migraine are higher than what is usually encountered with spinal cord stimulation ${ }^{13-15}$ despite identical hardware and similar surgery.

There are several possible reasons for the higher complication rate in these patients. There is a learning curve for any new procedure for both surgeons and referring physicians. Also the use of pre-operative psychological screening may reduce the number of psychiatric/psychological complications we encountered. The hardware used for OS was designed for epidural placement. The length of the lead and extension to an abdominal IPG site is long, thereby placing the system at higher risk for displacement. Ideally a shorter lead length, closer placement of the IPG to the site being stimulated or an IPG located within the leads themselves ${ }^{8,16}$ could reduce the risk of 
displacement. Presumed infection or inflammation occurred in $30 \%$ of patients, far higher than the $5 \%$ reported in the SCS population $^{15,17}$. The midline $\mathrm{C} 2$ insertion site may have contributed to infection risk, especially in obese patients with overlapping skin layers. This may be reduced by placement of the leads from lateral mastoid region incisions ${ }^{18}$. We can only speculate on the reasons why one large study reported a $24 \%$ lead displacement rate over the first three months postoperatively ${ }^{10}$ and another study reported only a $8 \%$ rate over two years ${ }^{11}$. While it may have to do with hardware specific to each company, it may also relate to how lead displacement was defined. For example, the PRISM study reported 'non-target area sensory symptoms' as a complication. It is possible that this was also related to lead displacement because if stimulation parameters were changed to cover the target territory, the region of paresthesia may also have altered and resulted in "non-target area sensory symptoms".

There has been minimal discussion in the literature about pain locations responding to OS. Originally OS was used to treat occipital neuralgia and the technique was to stimulate the nerve directly by exposing it and placing the stimulating lead beside $\mathrm{it}^{19}$. Later these patients were reclassified as suffering from chronic migraine rather than primary occipital neuralgia ${ }^{20}$. Recent studies seem to have expanded the indications for OS and include everything from fibromyalgia ${ }^{21}$ to unclassifiable facial pains $^{22}$. In addition, the larger studies have not defined location of pain clearly in their inclusion/exclusion criteria. That is why we operated on patients with such variable locations of pain. We found that those patients with primarily occipital pain were more likely to keep their OS systems after three years than those whose pain was more diffuse or located in other parts of the head and neck. While this should not be surprising, it has not been previously reported. Exact location of pain may not have concerned the trial designers because of the convergence of afferent input from dura supplied by trigeminal nerve and greater occipital $\mathrm{C} 2$ fibres onto the trigeminocervical complex in the brainstem and upper spinal cord ${ }^{22}$. Our finding that those patients with primarily occipital pain were more likely to keep their OS systems after three years than those whose pain was more diffuse or located in other parts of the head and neck requires confirmation in a larger patient group. If confirmed, it could provide prognostication, suggest appropriate patient selection, and may even suggest alternative hupotheses about OS mechanisms of action. Most recently electrodes have been placed in other head and neck sites ${ }^{23,24}$, likely because OS alone was not covering the area of pain. Perhaps patients with a lot of pain outside the occipital region may still be candidates for neuromodulation, but other regions may need to be stimulated as well.

\section{Conclusions}

In summary, while OS may be a reasonable treatment option for intractable migraine, the location of headache pain is an important determinant of long term outcome. In addition, complication rates, both surgical and psychiatric are higher than those seen with SCS and suggest that the instrumentation for OS as well as the screening criteria should be optimized for future clinical trials.

\section{ACKNOWLEDGEMENTS}

While the patients reported here were involved in a clinical trial funded by Medtronic Inc., the data collected and reported in this paper were not part of the data collected by the company. We thank Susan Anderson RN and Brenda Kelly-Besler RN for help with data collection and Drs. Lara Cooke and Arnolda Eloff for providing clinical information. Dr. Kiss was a Canadian Institutes of Health Research Clinician-Scientist (Phase 2) and a Clinical Scholar of the Alberta Heritage Foundation for Medical Research (AHFMR).

\section{Declaration}

This study was funded by Medtronic Inc. however the data presented here were entirely collected by the authors. Dr. Kiss receives grant funding unrelated to this study from CIHR and AHFMR. Dr. Becker has served on medical advisory boards for Merck, Allergan, Pfizer, and AGA Medical. He has also received speaker's honoraria from Teva, Serono, Merck, Allergan, and Pfizer, and research support as part of multicenter clinical trials from Allergan, Medtronic, AGA Medical, and Merck.

\section{REFERENCES}

1. Andlin-Sobocki P, Jonsson B, Wittchen HU, Olesen J. Cost of disorders of the brain in Europe. Eur J Neurol. 2005; 12(Suppl 1): $1-27$.

2. Leonardi M, Steiner TJ, Scher AT, Lipton RB. The global burden of migraine: measuring disability in headache disorders with WHO's Classification of Functioning, Disability and Health (ICF). J Headache Pain. 2005; 6(6): 429-40.

3. Olesen J, Bousser MG, Diener HC, et al. New appendix criteria open for a broader concept of chronic migraine. Cephalalgia. 2006; 26(6): 742-6.

4. Headache Classification Subcommittee of the International Headache Society. The International Classification of Headache Disorders: 2nd edition. Cephalalgia. 2004; 24(Suppl 1): 9-160.

5. Weiner RL, Reed KL. Peripheral stimulation for the control of intractable occipital neuralgia. Neuromodulation. 1999; 2(3): 217-21.

6. Bartsch T, Paemeleire K, Goadsby PJ. Neurostimulation approaches to primary headache disorders. Curr Opin Neurol. 2009; 22(3): 262-8.

7. Paemeleire K, Van Buyten JP, Van BM, et al. Phenotype of patients responsive to occipital nerve stimulation for refractory head pain. Cephalalgia. 2010; 30(6): 662-73.

8. Trentman TL, Rosenfeld DM, Vargas BB, Schwedt TJ, Zimmerman RS, Dodick DW. Greater occipital nerve stimulation via the Bion microstimulator: implantation technique and stimulation parameters. Clinical trial: NCT00205894. Pain Physician. 2009; 12(3): 621-8.

9. Schwedt TJ, Dodick DW, Hentz J, Trentman TL, Zimmerman RS. Occipital nerve stimulation for chronic headache--long-term safety and efficacy. Cephalalgia. 2007; 27(2): 153-7.

10. Saper JR, Dodick DW, Silberstein SD, McCarville S, Sun M, Goadsby PJ. Occipital nerve stimulation for the treatment of intractable chronic migraine headache: ONSTIM feasibility study. Cephalalgia. 2011; 31(3): 271-85.

11. Lipton RB, Goadsby PJ, Cady RK, et al. PRISM study: Occipital nerve stimulation for treatment refractory migraine. Cephalalgia. 2009; 29(Suppl 1): 30 (Abstract).

12. Silberstein SD, Dodick DW, Saper JR, et al. The safety and efficacy of peripheral nerve stimulation of the occipital nerve for the management of chronic migraine. Cephalalgia. 2011; 31(Suppl 1): 117 (Abstract)

13. Burchiel KJ, Anderson VC, Brown FD, et al. Prospective, multicenter study of spinal cord stimulation for relief of chronic back and extremity pain. Spine. 1996; 21(23): 2786-94. 
14. Kumar K, Taylor RS, Jacques L, et al. Spinal cord stimulation versus conventional medical management for neuropathic pain: a multicentre randomised controlled trial in patients with failed back surgery syndrome. Pain. 2007; 132(1-2): 179-88.

15. Kemler MA, Barendse GA, van Kleef M, et al. Spinal cord stimulation in patients with chronic reflex sympathetic dystrophy. N Engl J Med. 2000; 343(9): 618-24.

16. Burns B, Watkins L, Goadsby PJ. Treatment of hemicrania continua by occipital nerve stimulation with a bion device: long-term follow-up of a crossover study. Lancet Neurol. 2008; 7(11): 1001-12.

17. Ubbink DT, Vermeulen H, Spincemaille GH, Gersbach PA, Berg P, Amann W. Systematic review and meta-analysis of controlled trials assessing spinal cord stimulation for inoperable critical leg ischaemia. Br J Surg. 2004; 91(8): 948-55.

18. Trentman TL, Slavin KV, Freeman JA, Zimmerman RS. Occipital nerve stimulator placement via a retromastoid to infraclavicular approach: a technical report. Stereotact Funct Neurosurg. 2010; 88(2): $121-5$

19. Picaza JA, Hunter SE, Cannon BW. Pain suppression by peripheral nerve stimulation. Chronic effects of implanted devices. Appl Neurophysiol. 1977; 40(2-4): 223-4.
20. Matharu MS, Bartsch T, Ward N, Frackowiak RS, Weiner R, Goadsby PJ. Central neuromodulation in chronic migraine patients with suboccipital stimulators: a PET study. Brain. 2004; 127(Pt 1): 220-30.

21. Thimineur M, De Ridder D. C2 area neurostimulation: a surgical treatment for fibromyalgia. Pain Med. 2007; 8(8): 639-46.

22. Goadsby PJ, Bartsch T, Dodick DW. Occipital nerve stimulation for headache: mechanisms and efficacy. Headache. 2008; 48(2): 313-18.

23. Slavin KV. Peripheral nerve stimulation for the treatment of neuropathic craniofacial pain. Acta Neurochir. Suppl. 2007; 97(Pt 1): 115-20.

24. Reed KL, Black SB, Banta CJ, Will KR. Combined occipital and supraorbital neurostimulation for the treatment of chronic migraine headaches: initial experience. Cephalalgia. 2010; 30(3): 260-71. 